\title{
The Effects of Preoperative Coronary Collateral Circulation on Cardiac-Related Events after Coronary Artery Bypass Graft Surgery
}

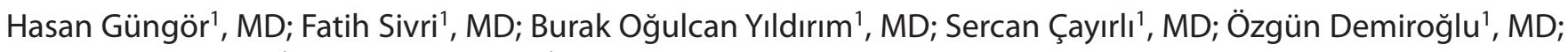 \\ Cem Utku Yeşilkaya ${ }^{1}$, MD; Cemil Zencir ${ }^{1}$, MD
}

DOI: $10.21470 / 1678-9741-2019-0375$

\section{Abstract}

Introduction: This study aimed to evaluate the effects of coronary collateral circulation (CCC) in patients who had undergone coronary artery bypass grafting (CABG).

Methods: A total of 127 patients who had undergone CABG (20112013) were enrolled into this study and follow-up was obtained by phone contact. Patients were categorized into two groups according to preoperative CCC using the Rentrop method. Percutaneous coronary intervention $(\mathrm{PCl})$, recurrent myocardial infarction (MI), stroke, heart failure (HF), and mortality rates were compared between groups. Clinical outcome was defined as combined end point including death, $\mathrm{PCl}$, recurrent $\mathrm{MI}$, stroke, and $\mathrm{HF}$.

Results: Sixty-two of 127 patients had poor CCC and 65 had good CCC. There were no differences in terms of $\mathrm{PCl}$, recurrent $\mathrm{MI}$,
\end{abstract}

and HF between the groups. Stroke (seven of 62 [11.3\%] and one of 65 [1.5\%], $P=0.026$ ) and mortality (19 of 62 [30.6\%] and 10 of $65[15.4 \%], P=0.033)$ rates were significantly higher in poor CCC group than in good CCC group. In Kaplan-Meier analysis, survival time was not statistically different between the groups. Presence of poor CCC resulted in a significantly higher combined end point incidence $(P=0.011)$.

Conclusion: Stroke, mortality rates, and combined end point incidence were significantly higher in poor CCC patients than in the good CCC group.

Keywords: Coronary Artery Bypass Graft Surgery. Coronary Collateral Circulation. Percutaneous Coronary Intervention. Myocardial Infarction. Heart Failure, Mortality.

\begin{tabular}{ll|ll}
\hline \multicolumn{2}{l}{ Abbreviations, acronyms \& symbols } & & \\
\hline ACE & = Angiotensin-converting enzyme & ICU & $=$ Intensive care unit \\
AF & = Atrial fibrillation & LA & $=$ Left atrial \\
BMI & $=$ Body mass index & LDL & $=$ Low-density lipoprotein \\
CABG & $=$ Coronary artery bypass grafting & LV & $=$ Left ventricular \\
CAD & $=$ Coronary artery disease & LVEF & $=$ Left ventricular ejection fraction \\
CC & $=$ Cross-clamp & MI & $=$ Myocardial infarction \\
CCC & $=$ Coronary collateral circulation & OR & $=$ Odds ratio \\
CI & $=$ Confidence interval & OS & $=$ Overall survival \\
COPD & $=$ Chronic obstructive pulmonary disease & PCI & $=$ Percutaneous coronary intervention \\
DM & $=$ Diabetes mellitus & RCA & $=$ Right coronary artery \\
HF & $=$ Heart failure & RR & $=$ Relative risk \\
HT & $=$ Hypertension & & \\
& & & \\
\hline & & &
\end{tabular}

'Department of Cardiology, Adnan Menderes University, Aydin, Turkey.

This study was carried out at the Department of Cardiology, Adnan Menderes University, Aydin, Turkey.
Correspondence Address:

Hasan Gungor

(iD) https://orcid.org/0000-0002-4462-3029

Department of Cardiology, Adnan Menderes University, Merkez Kampüs Efeler/Aydin, Turkey - Zip Code: 09100

E-mail: drgungorhasan@yahoo.com 


\section{INTRODUCTION}

The myocardial area at risk for infarction, duration of occlusion, absence of coronary collateral circulation (CCC), absence of ischemic preconditioning, and myocardial oxygen consumption during occlusion are the factors which affect the myocardial infarct size ${ }^{[1,2]}$. Theoretically, CCC is an alternative source of blood supply to ischemic myocardium and one of the most important factors of the rate and extent of myocardial cell death ${ }^{[3]}$; however, its prognostic importance for patients with coronary artery disease (CAD) has been still controversial[4,5].

Coronary artery bypass grafting (CABG) is still the standard care for patients with three-vessel or left main CAD with intermediate or high SYNTAX score (> 22), compared with the percutaneous coronary intervention $(\mathrm{PCl})^{[6,7]}$. The $\mathrm{CCC}$ behaves as an alternative source of blood supply in patients with myocardial infarction (MI) and may reduce infarct size and remodel the left ventricle. In literature, there are several publications regarding the benefits of CCC — reducing the tissue injury - in patients with $\mathrm{MI}^{[8-10]}$; however, there are limited data on the collateral effects on prognosis and survival in patients who had undergone $\mathrm{CABG}^{[11-13]}$. The purpose of this study was to explore the impact of CCC in terms of $\mathrm{PCl}$, recurrent $\mathrm{Ml}$, stroke, heart failure, and mortality rates in patients who had undergone CABG.

\section{METHODS}

After approval by the local research ethics committee, the present study was conducted as a follow-up study. In our previous study, we conducted a trial to assess the association between poor CCC and atrial fibrillation (AF) after $\mathrm{CABG}^{[14]}$. One hundred sixty-five consecutive patients who were found to have $>95 \%$ stenosis in at least one major coronary artery in the coronary angiogram and had undergone CABG between 2011 and 2013 at our department had been included in our previous study. Case selection and exclusion criteria were similar to that described in the authors' previous studies ${ }^{[14]}$. Institutional review board approval was obtained for the present study. By using phone contact, five outcome variables were monitored continuously: $\mathrm{PCl}$, recurrent $\mathrm{Ml}$, stroke, heart failure, and mortality rates. In 2019, all of those patients were called by phone, 127 of 165 patients were reached and enrolled into our study.

Details of the baseline clinical characteristics, preoperative treatment, echocardiographic and angiographic findings, and intraoperative and postoperative parameters were recorded. Hypertension was defined as blood pressure $>140 / 90 \mathrm{mmHg}$ on more than two occasions during office measurements or being on antihypertensive treatment. Diabetes mellitus (DM) was defined as fasting blood glucose of at least $126 \mathrm{mg} / \mathrm{dl}$ or being on antidiabetic treatment. Hyperlipidemia was defined as follows: serum low-density lipoprotein cholesterol > $160 \mathrm{mg} / \mathrm{dl}$ or total cholesterol $>240 \mathrm{mg} / \mathrm{dl}$ or triglyceride $>200 \mathrm{mg} / \mathrm{dl}$ or high-density lipoprotein cholesterol $<40 \mathrm{mg} / \mathrm{dl}$ or those taking lipid-lowering drugs. Echocardiographic examinations were performed using an iE33 cardiac ultrasound system (Phillips Healthcare, Best, The Netherlands) with $2.5-5-\mathrm{MHz}$ probes. Ejection fraction was calculated using the modified Simpson method.

\section{Coronary Collateral Scoring}

The collateral scoring and the collateral branches evaluation was performed by a single tool developed by Cohen and Rentrop in their study ${ }^{[15]}$. Grades of collateral filling from the contralateral vessel were as follows: 0 , none; 1 , filling of side branches of the artery to be dilated by collateral channels without visualization of the epicardial segment; 2 , partial filling of the epicardial segment by collateral channels; and 3, complete filling of the epicardial segment of the artery being dilated by collateral channels. In patients with more than one collateral vessel supplying the distal aspect of the diseased artery, the highest collateral grade was recorded. Patients were classified according to their CCC grades as either poor (grade 0 or grade 1 collateral circulation) or good (grade 2 or grade 3 collateral circulation) ${ }^{[16]}$.

\section{Statistical Analysis}

The normal distribution of the variables was analyzed by the Kolmogorov-Smirnov test. Normally distributed variables were presented as mean and standard deviation and were compared using the Student's t-test, while non-normally distributed variables were presented as median and its interquartile range and were compared using nonparametric tests such as the Mann-Whitney two-sample test. The rate or percentile of the parameters were compared by using Chi-square $\left(x^{2}\right)$ test. The presence of the CCC as a dependent factor and the dichotomous variables, $\mathrm{PCl}$, recurrent $\mathrm{Ml}$, stroke, heart failure, and mortality rates, were analyzed as covariates for the binary logistic regression models. Overall survival (OS) was calculated through a Kaplan-Meier analysis and was presented as the median and 95\% confidence interval (CI). A P-value $<0.05$ indicated statistical significance. Statistical analysis was performed using the SPSS Inc. Released 2008; SPSS Statistics for Windows, Version 17.0; Chicago: SPSS Inc.

\section{RESULTS}

A total of 127 patients (93 males and 34 females) who had undergone $C A B G$ at our department were reached by phone contact and enrolled into our study. Of the patients, 62 had poor CCC and 65 had good CCC. The mean age of the patients was $65.0 \pm 9.5$ years in the poor CCC group and $62.6 \pm 9.9$ years in the good CCC group. Hypertension rate, hyperlipidemia rate, smoking, chronic obstructive pulmonary disease rate, pre-treatment use of beta-blockers, angiotensin-converting enzyme inhibitors, calcium channel blockers, and antiplatelet agents were similar among groups. Stroke and DM rates were significantly higher in the poor CCC group than in the good CCC group (seven of 62 [11.3\%] and one of $65[1.5 \%], P=0.030$, and 34 of 62 [54.8\%] and 25 of 65 [38.5\%], $P=0.047$, respectively) (Table 1 ).

When we evaluated the echocardiographic parameters of the patients, we found that left atrial size and left ventricular ejection fraction percentile were higher in the poor CCC group than in the good CCC group $(3.9 \pm 0.4 \mathrm{~cm}$ and $3.7 \pm 0.3 \mathrm{~cm}$, $P=0.045$, and $55.3 \pm 10.6 \%$ and $48.1 \pm 10.6, P=0.003$, respectively). Mean left ventricular systolic and diastolic diameters were similar among groups (Table 2). 
Table 1. Preoperative comparison between the patients' clinical features.

\begin{tabular}{|c|c|c|c|}
\hline Variables & $\begin{array}{l}\text { Poor CCC (Rentrop 0-1) } \\
\qquad n=62\end{array}$ & $\begin{array}{l}\text { Good CCC (Rentrop 2-3) } \\
\qquad n=65\end{array}$ & $P$-value \\
\hline Age (years) & $65.0 \pm 9.5$ & $62.6 \pm 9.9$ & 0.726 \\
\hline Male, n (\%) & $44(71 \%)$ & $49(75.4 \%)$ & 0.689 \\
\hline $\mathrm{BMI}\left(\mathrm{kg} / \mathrm{m}^{2}\right)$ & $29.0 \pm 5.9$ & $28.6 \pm 4.3$ & 0.130 \\
\hline Follow-up period (years) & $6.6 \pm 1.7$ & $6.5 \pm 1.5$ & 0.885 \\
\hline Stroke, n (\%) & $7(11.3)$ & $1(1.5)$ & 0.030 \\
\hline $\mathrm{HT}, \mathrm{n}(\%)$ & $40(64.5)$ & $44(67.7)$ & 0.424 \\
\hline Hyperlipidemia, n (\%) & $17(27.4)$ & $14(21.5)$ & 0.286 \\
\hline $\mathrm{DM}, \mathrm{n}(\%)$ & $34(54.8)$ & $25(38.5)$ & 0.047 \\
\hline Smoking, n (\%) & $31(50)$ & $36(55.4)$ & 0.334 \\
\hline COPD, n (\%) & $7(11.3)$ & $6(9.2)$ & 0.464 \\
\hline$\beta$-blockers, n (\%) & $52(83.9)$ & $55(84.6)$ & 0.550 \\
\hline ACE inhibitors, n (\%) & $32(51.6)$ & $30(46.2)$ & 0.331 \\
\hline Calcium channel blockers, n (\%) & $11(17.7)$ & $8(12.3)$ & 0.271 \\
\hline Antiplatelet agents, (\%) & $17(27.4)$ & $17(26.2)$ & 0.515 \\
\hline
\end{tabular}

Data of variables are expressed as mean \pm standard deviation (range) or absolute number and its frequencies, $\mathrm{n}$ (\%) $\mathrm{ACE}=$ angiotensin-converting enzyme; $\mathrm{BMI}=$ body mass index; $C C C=$ coronary collateral circulation; $C O P D=$ chronic obstructive pulmonary disease; $\mathrm{DM}=$ diabetes mellitus; $\mathrm{HT}=$ hypertension

Table 2. Preoperative comparison between the patients' laboratory and echocardiographic parameters.

\begin{tabular}{|c|c|c|c|}
\hline Variables & $\begin{array}{l}\text { Poor CCC (Rentrop 0-1) } \\
\qquad n=62\end{array}$ & $\begin{array}{l}\text { Good CCC (Rentrop 2-3) } \\
\qquad n=65\end{array}$ & $P$-value \\
\hline Blood glucose (mg/dl) & $134.3 \pm 78.0$ & $131.2 \pm 58.8$ & 0.800 \\
\hline Creatinine (mg/dl) & $1.2 \pm 1.3$ & $0.9 \pm 0.3$ & 0.195 \\
\hline Aspartate aminotransferase (IU/I) & $33.6 \pm 59.0$ & $37.5 \pm 39.9$ & 0.662 \\
\hline Alanine aminotransferase (IU/I) & $21.1 \pm 12.6$ & $31.8 \pm 34.8$ & 0.026 \\
\hline Hemoglobin (g/dl) & $12.7 \pm 1.7$ & $13.5 \pm 1.7$ & 0.009 \\
\hline Platelet counts ('10³/ml) & $261 \pm 88$ & $265 \pm 99$ & 0.833 \\
\hline $\mathrm{LDL}(\mathrm{mg} / \mathrm{dl})$ & $110.5 \pm 30.2$ & $120.0 \pm 60.8$ & 0.365 \\
\hline Total cholesterol (mg/dl) & $180.4 \pm 37.9$ & $191.1 \pm 69.2$ & 0.362 \\
\hline Triglyceride (mg/dl) & $157.3 \pm 84.2$ & $184.4 \pm 114.0$ & 0.195 \\
\hline LA size $(\mathrm{cm})$ & $3.9 \pm 0.4$ & $3.7 \pm 0.3$ & 0.045 \\
\hline LV systolic diameter (cm) & $3.5 \pm 0.6$ & $3.8 \pm 0.7$ & 0.056 \\
\hline LV ejection fraction (\%) & $55.3 \pm 10.6$ & $48.1 \pm 10.6$ & 0.003 \\
\hline LV diastolic diameter (cm) & $6.5 \pm 8.5$ & $5.4 \pm 0.6$ & 0.418 \\
\hline ICU (hours) & $78.4 \pm 64.4$ & $60.4 \pm 29.3$ & 0.043 \\
\hline
\end{tabular}

Data of variables are expressed as mean \pm standard deviation (range)

$C C C=$ coronary collateral circulation; ICU=intensive care unit; $L A=l$ eft atrial; $L D L=l o w$-density lipoprotein; $L V=L e f t$ ventricular 
Intraoperative and postoperative data of the patients in the study were depicted in Table 3. Cross-clamp time, number of distal anastomoses, extubation time, and right coronary artery bypass rates were similar among groups (Table 3 ). When we compared the rates of cardiac-related events in terms of recurrent $\mathrm{Ml}$, recurrent $\mathrm{PCl}$, heart failure, stroke, and mortality, we found that stroke and death rates were significantly higher in the poor CCC group than in the good CCC group (seven [11.3\%] and one [1.5\%], $P=0.026$, and 19 [30.6\%] and 10 [15.4\%], $P=0.033$, respectively) (Table 4). There were no differences in other cardiacrelated events among groups.

Univariate logistic regression analyses showed that good CCC significantly decrease the risk of mortality after CABG (odds ratio $=0.411,95 \% \mathrm{Cl}=0.174-0.976 ; P=0.044)$ (Table 5$)$. OS of patients with poor CCC (Rentrop 0-1) and good CCC (Rentrop 2-3) who had undergone CABG was assessed by Kaplan-Meier analysis. In Kaplan-Meier analysis, survival time was not statistically different between the groups ( $P=0.088$ ) (Table 6) (Figure 1). Combined end point incidence of cardiac-related events, including $\mathrm{PCl}$, recurrent $\mathrm{MI}$, stroke, and heart failure, in patients with poor CCC (Rentrop 0-1) and good CCC (Rentrop 2-3) who had undergone
CABG were assessed by Kaplan-Meier analysis. Presence of poor coronary collaterals resulted in a significantly higher combined end point incidence in cardiac-related events ( $P=0.011$ ).

\section{DISCUSSION}

In the current study, we found that stroke and mortality rates were significantly higher in the poor CCC group than in the good CCC group. Patients with good CCC had longer survival time than patients with poor CCC, however this difference did not yield a significantly better median OS.

Theoretically, CCC is an important alternative blood supply in case of $\mathrm{MI}^{[3]}$. However, it is still not well known how this protective mechanism works ${ }^{[4,5]}$. Acute $\mathrm{Ml}$ leads to longer QT interval and this situation increases the risk of arrhythmias. CCC may reduce the QT interval and the risk of arrhythmias ${ }^{[17]}$. In our previous study, we found that patients with poor CCC had a higher risk for AF after $C A B G^{[14]}$. We speculated that good CCC may affect the occurrence of AF after CABG by reducing atrial ischemia, oxidative damage, inflammation, fibrosis, lipid deposition, and dilatation $^{[14]}$. Also, CCC has positive clinical effects through

Table 3. Patients' intraoperative and postoperative data.

\begin{tabular}{l|c|c|c}
\hline \multicolumn{1}{c|}{ Variables } & $\begin{array}{c}\text { Poor CCC (Rentrop 0-1) } \\
\mathbf{n = 6 2}\end{array}$ & $\begin{array}{c}\text { Good CCC (Rentrop 2-3) } \\
\mathbf{n = 6 5}\end{array}$ & P-value \\
\hline & & & 0.635 \\
\hline CC time (min) & $52.9 \pm 25.4$ & $2.9 \pm 0.7$ & 0.792 \\
\hline Number of distal anastomoses (n) & $2.9 \pm 0.8$ & $18.3 \pm 17.7$ & 0.543 \\
\hline Extubation time (h) & $20.5 \pm 22.7$ & $46(70.8)$ & 0.226 \\
\hline
\end{tabular}

Data of variables are expressed as mean \pm standard deviation (range) or absolute number and its frequencies, $\mathrm{n}$ (\%)

$C C=$ cross-clamp; $C C C=$ coronary collateral circulation; $\mathrm{RCA}=$ right coronary artery

Table 4. Postoperative comparison between the patients' cardiac-related events.

\begin{tabular}{l|c|c|c}
\hline \multicolumn{1}{c|}{ Variables } & Poor CCC (Rentrop 0-1) & Good CCC (Rentrop 2-3) & P-value \\
\hline Recurrent MI, n (\%) & $\mathrm{n}=62$ & $\mathrm{n}=65$ & $8(12.3)$ \\
\hline Recurrent PCl, n (\%) & $2(3.2)$ & $6(9.2)$ & 0.056 \\
\hline Heart failure, n (\%) & $11(17.7)$ & $7(10.8)$ & 0.126 \\
\hline Stroke, $\mathrm{n}(\%)$ & $13(21.0)$ & $1(1.5)$ & 0.091 \\
\hline Mortality, $\mathrm{n}(\%)$ & $7(11.3)$ & $10(15.4)$ & 0.033 \\
\hline Total & $19(30.6)$ & $20(30.1)$ & $<0.001$ \\
\hline
\end{tabular}

Data of variables are expressed as absolute number and its frequencies, $\mathrm{n}(\%)$.

$C C C=$ coronary collateral circulation; $\mathrm{Ml}=$ myocardial infarction; $\mathrm{PCl}=$ percutaneous coronary intervention; Total=any cardiac-related event 
Table 5. Univariate logistic regression analyses for predicting the effect of good CCC on cardiac-related events after CABG.

\section{Good CCC (Rentrop 2-3)}

\begin{tabular}{|c|c|c|}
\hline & OR 95\% (Cl) & $P$-value \\
\hline \multirow{2}{*}{ Recurrent Ml } & 4.211 & \multirow{2}{*}{0.077} \\
\hline & $(0.857-20.675)$ & \\
\hline \multirow{2}{*}{ Recurrent $\mathrm{PCl}$} & 0.471 & \multirow{2}{*}{0.166} \\
\hline & $(0.163-1.365)$ & \\
\hline \multirow{2}{*}{ Heart failure } & 0.455 & \multirow{2}{*}{0.121} \\
\hline & $(0.168-1.230)$ & \\
\hline \multirow{2}{*}{ Stroke } & 0.123 & \multirow{2}{*}{0.053} \\
\hline & $(0.015-1.029)$ & \\
\hline \multirow{2}{*}{ Mortality } & 0.411 & \multirow{2}{*}{0.044} \\
\hline & $(0.174-0.976)$ & \\
\hline
\end{tabular}

$\mathrm{CABG}=$ coronary artery bypass grafting; $C \mathrm{CC}=$ coronary collateral circulation; $\mathrm{Cl}=$ confidence interval; $\mathrm{Ml}=$ myocardial infarction; $\mathrm{OR}=$ odds ratio; $\mathrm{PCl}=$ percutaneous coronary intervention

Table 6. Overall survival of patients with poor CCC (Rentrop 0-1) and good CCC (Rentrop 2-3) who had undergone CABG as assessed by Kaplan-Meier analysis.

\begin{tabular}{c|c|c|c}
\hline Variables & $\begin{array}{c}\text { Poor CCC (Rentrop 0-1) } \\
\mathbf{n = 6 2}\end{array}$ & $\begin{array}{c}\text { Good CCC (Rentrop 2-3) } \\
\mathbf{n = 6 5}\end{array}$ & $\boldsymbol{P}$-value \\
\hline Mean survival (years) & $7.5 \pm 0.2$ & $7.1 \pm 0.2$ & 0.088 \\
\hline Cl (95\%) & $7.1-7.8$ & $6.6-7.6$ & \\
\hline
\end{tabular}

$\mathrm{CABG}=$ coronary artery bypass grafting; $C C C=$ coronary collateral circulation; $\mathrm{Cl}=$ confidence interval

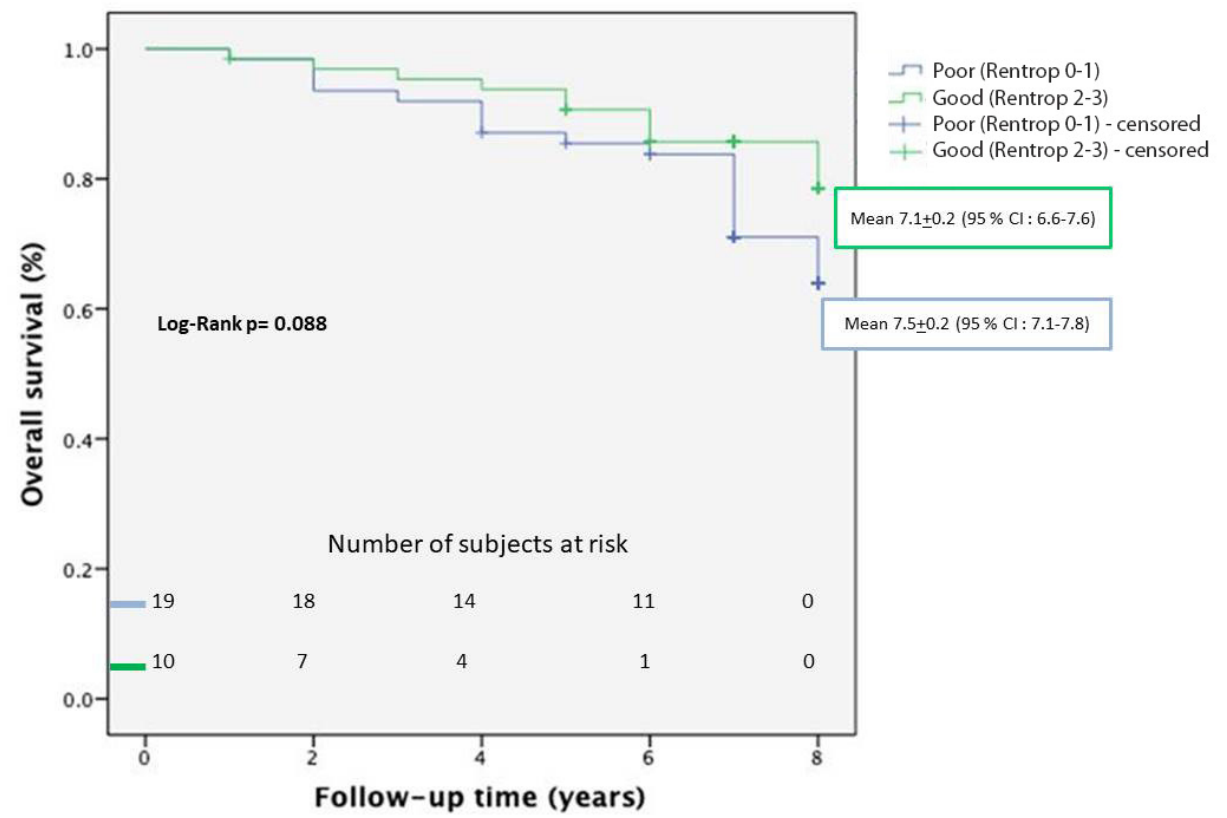

Fig. 1 - Kaplan-Meier analysis. Cl=confidence interval 
smaller infarct size and reduction in post-infarct ventricular dilatation. All those described prognostic factors should reduce the cardiac-related event rate and have clinical beneficial effects on reducing mortality ${ }^{[18]}$.

In a meta-analysis, it was reported that patients with a high collateralization had a significantly reduced mortality risk compared with patients with low collateralization (relative risk $[R R]=0.64)^{[5]}$. Those results were comparable with our study. In our study, we showed that good CCC reduced the mortality risk in patients who had undergone $C A B G(R R=0.411)$. However, in the current study, we found that left ventricular ejection fraction (LVEF) was significantly lower in the good CCC group than in the poor CCC group $(48.1 \pm 10.6 \%$ vs. $55.3 \pm 10.6 \%, P=0.003$, respectively). This is an interesting finding, because we expect that good CCC prevents the myocardium from ischemia and tissue injury; consequently, it provides higher LVEF as it was shown in previous studies ${ }^{[2,3]}$. However, similarly to our study, Caputo et al. ${ }^{[13]}$ and Regieli et al. ${ }^{[19]}$ have found that patients with good CCC had lower LVEF than patients with poor CCC. The development of CCC should be considered as a result of angina and more severe and extensive myocardial ischemia of multivessel disease ${ }^{[20]}$.

Tatli et al. ${ }^{[12]}$ compared medical therapy and CABG in patients with good CCC and they reported that revascularization did not affect mortality in patients with CCC. The follow-up period was five years and the rate of survival did not differ among groups in that study. In an another study comparing the effects of CCC after $C A B G$, survival rate in five years was similar between the poor and good CCC groups (84.8\% in the CCC group and $89.2 \%$ in the no-CCC group) $)^{[13]}$. Cardiac-related event-free survival after five years was $50.6 \%$ in the CCC group and $54.5 \%$ in the no-CCC group with no significant differences between both groups, as well[13]. However, in the present study, survival rate was found to be significantly higher in the good CCC group than in the poor CCC group (84.6\% and $69.4 \%$, respectively), and cardiacrelated event-free survival was significantly higher in the good CCC group than in the poor CCC group $(69.9 \%$ and $32.3 \%$, respectively).

In our study, we found that stroke rate was significantly higher in the poor CCC group than in the good CCC group (seven of 62 [11.3\%] vs. one of 65 [1.5\%], respectively). This finding may be associated with the AF rate in the study population. As previously reported, AF was associated with high stroke incidence rate ${ }^{[21]}$. In our previous study including the similar patient population (we could not reach all the patients at the follow-up period), we reported that the AF rate in the poor CCC group was significantly higher than in the good CCC group (37 of 76 [49\%] vs. 12 of 89 [14\%], $P<0.001$, respectively ${ }^{[14]}$.

Combined end point incidence of cardiac-related events, including $\mathrm{PCl}$, recurrent $\mathrm{MI}$, stroke, and heart failure, in patients with poor CCC (Rentrop 0-1) and good CCC (Rentrop 2-3) who had undergone CABG were assessed by Kaplan-Meier analysis. Presence of poor coronary collaterals resulted in a significantly higher combined end point incidence in cardiac-related events $(P=0.011)$. In the present study, the follow-up period was $6.6 \pm 1.7$ years in the poor CCC group and $6.5 \pm 1.5$ years in the good CCC group. The follow-up period should be considered relatively short. In our opinion, higher incidence of cardiac-related events in patients with poor CCC may result in increased mortality rate in a longer follow-up period in those patients.

In the present study, we found that recurrent MI rate was higher in the good CCC group than in the poor CCC group (eight of 65 [12.3\%] vs. two of 62 [3.2\%], $P=0.056$, respectively), but it did not reach a statistically significant value. Our findings are consistent with the competition theory ${ }^{[3]}$. Good CCC may affect negatively coronary arteries such as coronary steal during myocardial hyperaemia by competing antegrade flow ${ }^{[3]}$. This situation may increase the risk of restenosis by reducing the flow velocity at the ischemic field with augmented platelet adherence, thrombus formation, and endothelial proliferation ${ }^{[3]}$.

\section{Limitations}

The major limitations of the current study were the relatively small number of patients and the loss of follow-up of almost 40 patients, which can affect the results.

\section{CONCLUSION}

We found that patients with poor CCC may have a higher risk for cardiac-related events including stroke and mortality after CABG surgery. Although there were no significant differences for OS between the poor and good CCC groups, the patients with good CCC had longer survival time than the patients with poor CCC. Further prospective, randomized, controlled trials are needed to confirm the effects of CCC on cardiac-related events.

\section{No financial support. \\ No conflict of interest.}

\section{Authors' roles \& responsibilities}

HG Substantial contributions to the conception or design of the work; and analysis of data for the work; drafting the work or revising it critically for important intellectual content; final approval of the version to be published

FS Substantial contributions to the conception or design of the work; final approval of the version to be published

BOY Analysis of data for the work; final approval of the version to be published

SC Analysis of data for the work; final approval of the version to be published

OD Interpretation of data for the work; final approval of the version to be published

CUY Substantial contributions to the conception or design of the work; final approval of the version to be published

CZ Acquisition of data for the work; final approval of the version to be published 


\section{REFERENCES}

1. Schaper W, Frenzel H, Hort W. Experimental coronary artery occlusion. I. Measurement of infarct size. Basic Res Cardiol. 1979;74(1):46-53. doi:10.1007/BF01907684.

2. Reimer KA, Ideker RE, Jennings RB. Effect of coronary occlusion site on ischaemic bed size and collateral blood flow in dogs. Cardiovasc Res. 1981;15(11):668-74. doi:10.1093/cvr/15.11.668.

3. Seiler $C$, Meier P. Historical aspects and relevance of the human coronary collateral circulation. Curr Cardiol Rev. 2014;10(1):2-16. doi:10.2174/15 73403×113099990028.

4. Meier P, Gloekler S, Zbinden R, Beckh S, de Marchi SF, Zbinden S, et al. Beneficial effect of recruitable collaterals: a 10-year follow-up study in patients with stable coronary artery disease undergoing quantitative collateral measurements. Circulation. 2007;116(9):975-83. doi:10.1161/ CIRCULATIONAHA.107.703959.

5. Meier P, Hemingway H, Lansky AJ, Knapp G, Pitt B, Seiler C. The impact of the coronary collateral circulation on mortality: a meta-analysis. Eur Heart J. 2012;33(5):614-21. doi:10.1093/eurheartj/ehr308.

6. Neumann FJ, Sousa-Uva M, Ahlsson A, Alfonso F, Banning AP, Benedetto $U$, et al. 2018 ESC/EACTS guidelines on myocardial revascularization. Eur Heart J. 2019;40(2):87-165. doi:10.1093/eurheartj/ehy394.

7. Serruys PW, Morice MC, Kappetein AP, Colombo A, Holmes DR, Mack MJ, et al. Percutaneous coronary intervention versus coronaryartery bypass grafting for severe coronary artery disease. N Engl J Med. 2009;360(10):961-72. Erratum in: N Engl J Med. 2013;368(6):584. doi:10.1056/NEJMoa0804626.

8. Habib GB, Heibig J, Forman SA, Brown BG, Roberts R, Terrin ML, et al. Influence of coronary collateral vessels on myocardial infarct size in humans. Results of phase I thrombolysis in myocardial infarction (TIMI) trial. The TIMI investigators. Circulation. 1991;83(3):739-46. doi:10.1161/01.cir.83.3.739.

9. Charney R, Cohen M. The role of the coronary collateral circulation in limiting myocardial ischemia and infarct size. Am Heart J. 1993;126(4):93745. doi:10.1016/0002-8703(93)90710-q.

10. Sabia PJ, Powers ER, Ragosta M, Sarembock IJ, Burwell LR, Kaul S. An association between collateral blood flow and myocardial viability in patients with recent myocardial infarction. N Engl J Med. 1992;327(26):1825-31. doi:10.1056/NEJM199212243272601.

11. Nathoe HM, Buskens E, Jansen EW, Suyker WJ, Stella PR, Lahpor JR, et al. Role of coronary collaterals in off-pump and on-pump coronary bypass surgery. Circulation. 2004;110(13):1738-42. doi:10.1161/01. CIR.0000143105.42988.FD.

12. Tatlı E, Aktoz M, Çakar MA, Doğan E, Alkan M, Özalp B. Survival of patients with well-developed collaterals undergoing CABG or medical treatment: an observational case-controlled study. Anadolu Kardiyol Derg. 2012;12(2):97-101. doi:10.5152/akd.2012.033.

13. Caputo M, Anis RR, Rogers CA, Ahmad N, Rizvi SI, Baumbach A, et al. Coronary collateral circulation: effect on early and midterm outcomes after off-pump coronary artery bypass surgery. Ann Thorac Surg. 2008;85(1):71-9. doi:10.1016/j.athoracsur.2007.08.026.

14. Gungor H, Eryilmaz U, Akgullu C, Zencir C, Kurtoglu T, Selvi M, et al. Preoperative poor coronary collateral circulation can predict the development of atrial fibrillation after coronary artery bypass graft surgery. Coron Artery Dis. 2013;24(7):572-6. doi:10.1097/ MCA.0000000000000025.

15. Cohen M, Rentrop KP. Limitation of myocardial ischemia by collateral circulation during sudden controlled coronary artery occlusion in human subjects: a prospective study. Circulation. 1986;74(3):469-76. doi:10.1161/01.cir.74.3.469.

16. Rentrop KP, Cohen M, Blanke H, Phillips RA. Changes in collateral channel filling immediately after controlled coronary artery occlusion by an angioplasty balloon in human subjects. J Am Coll Cardiol. 1985;5(3):58792. doi:10.1016/s0735-1097(85)80380-6.

17. Meier P, Gloekler S, de Marchi SF, Zbinden R, Delacrétaz E, Seiler C. An indicator of sudden cardiac death during brief coronary occlusion: electrocardiogram QT time and the role of collaterals. Eur Heart J. 2010;31(10):1197-204. doi:10.1093/eurheartj/ehp576.

18. Seiler C. Collateral Circulation of the Heart. London: Springer; 2009. Chapter 1.4: Collective prognostic relevance. p.46-56.

19. Regieli JJ, Jukema JW, Nathoe HM, Zwinderman AH, Ng S, Grobbee $D E$, et al. Coronary collaterals improve prognosis in patients with ischemic heart disease. Int J Cardiol. 2009;132(2):257-62. doi:10.1016/j. ijcard.2007.11.100.

20. Selçuk MT, Selçuk H, Temizhan A, Maden O, Ulupinar H, Baysal E, et al. [The effect of plasma asymmetric dimethylarginine (ADMA) level and L-arginine/ADMA ratio on the development of coronary collaterals]. Turk Kardiyol Dern Ars. 2008;36(3):150-5. Turkish.

21. Knijnik L, Rivera M, BlumerV, Cardoso R, Fernandes A, Fernandes G, et al. Prevention of stroke in atrial fibrillationaAfter coronary stenting. Stroke. 2019;50(8):2125-32. doi:10.1161/STROKEAHA.119.026078. 